\title{
Virus-like particle size and molecular weight/mass determination applying gas-phase electrophoresis (native nES GEMMA)
}

\author{
Victor U. Weiss ${ }^{1} \cdot$ Ronja Pogan ${ }^{2,3} \cdot$ Samuele Zoratto ${ }^{1} \cdot$ Kevin M. Bond ${ }^{4} \cdot$ Pascale Boulanger $^{5} \cdot$ Martin F. Jarrold $^{4}$. \\ Nicholas Lyktey ${ }^{4}$. Dominik Pahl ${ }^{6}$. Nicole Puffler ${ }^{1} \cdot$ Mario Schelhaas $^{6}$ • Ekaterina Selivanovitch ${ }^{4}$. \\ Charlotte Uetrecht ${ }^{2,3} \cdot$ Günter Allmaier ${ }^{1}$
}

Received: 16 April 2019 / Revised: 29 May 2019 / Accepted: 24 June 2019 / Published online: 6 July 2019

(C) The Author(s) 2019

\begin{abstract}
(Bio-)nanoparticle analysis employing a nano-electrospray gas-phase electrophoretic mobility molecular analyzer (native nES GEMMA) also known as nES differential mobility analyzer (nES DMA) is based on surface-dry analyte separation at ambient pressure. Based on electrophoretic principles, single-charged nanoparticles are separated according to their electrophoretic mobility diameter (EMD) corresponding to the particle size for spherical analytes. Subsequently, it is possible to correlate the (bio-)nanoparticle EMDs to their molecular weight $\left(\mathrm{M}_{\mathrm{W}}\right)$ yielding a corresponding fitted curve for an investigated analyte class. Based on such a correlation, (bio-)nanoparticle $\mathrm{M}_{\mathrm{W}}$ determination via its EMD within one analyte class is possible. Turning our attention to icosahedral, non-enveloped virus-like particles (VLPs), proteinaceous shells, we set up an EMD/M $\mathrm{M}_{\mathrm{W}}$ correlation. We employed native electrospray ionization mass spectrometry (native ESI MS) to obtain $\mathrm{M}_{\mathrm{W}}$ values of investigated analytes, where possible, after extensive purification. We experienced difficulties in native ESI MS with time-of-flight (ToF) detection to determine $\mathrm{M}_{\mathrm{W}}$ due to sample inherent characteristics, which was not the case for charge detection (CDMS). nES GEMMA exceeds CDMS in speed of analysis and is likewise less dependent on sample purity and homogeneity. Hence, gas-phase electrophoresis yields calculated $\mathrm{M}_{\mathrm{W}}$ values in good approximation even when charge resolution was not obtained in native ESI ToF MS. Therefore, both methods-native nES GEMMA-based $\mathrm{M}_{\mathrm{W}}$ determination via an analyte class inherent EMD/M correlation and native ESI MS-in the end relate (bio-)nanoparticle $\mathrm{M}_{\mathrm{W}}$ values. However, they differ significantly in, e.g., ease of instrument operation, sample and analyte handling, or costs of instrumentation.
\end{abstract}

Keywords Native nES GEMMA $\cdot$ DMA $\cdot$ VLP $\cdot$ Molecular weight/mass $\cdot$ Size $\cdot$ Mass spectrometry

Victor U. Weiss and Ronja Pogan contributed equally to this work.

Electronic supplementary material The online version of this article (https://doi.org/10.1007/s00216-019-01998-6) contains supplementary material, which is available to authorized users.

Victor U. Weiss

victor.weiss@tuwien.ac.at

1 Institute of Chemical Technologies and Analytics, TU Wien, Getreidemarkt 9/164, 1060 Vienna, Austria

2 Heinrich Pette Institute, Leibniz Institute for Experimental Virology, Martinistraße 52, 20251 Hamburg, Germany

3 European XFEL GmbH, Holzkoppel 4, 22869 Schenefeld, Germany
4 Department of Chemistry, Indiana University, 800 E Kirkwood Ave, Bloomington, IN 47405, USA

5 Institute for Integrative Biology of the Cell, CEA, CNRS, Université Paris-Sud, Université Paris-Saclay, 91198 Gif-sur-Yvette, France

6 Institute of Cellular Virology, WWU Münster, Von-Esmarch-Str. 56, 48149 Münster, Germany 


\section{Introduction}

Viruses are nanoparticles of biological origin: A proteinaceous capsid protects the viral genome from the exterior. Additional protection can be conveyed by a lipid membrane, which is additionally modified by (glyco-) proteins to enable attachment to target cells (e.g., [1]). Only upon target cell infection, the genomic material of the virus is intended for release. This concept is of interest for pharmacological applications as virus bionanoparticles can be interpreted as carriers enabling the shielded, targeted transport of cargo material. Alternatively, viral particles without any encapsulated cargo can be employed for vaccination. In both cases, corresponding particles are referred to as virus-like particles (VLPs) (e.g., [2]).

To allow for VLP application in the field of pharmaceutics, their thorough characterization and preparation batch control, e.g., in terms of particle homogeneity, purity of preparations, particle size, and molecular weight $\left(\mathrm{M}_{\mathrm{W}}\right)$, is of importance. For the latter, native electrospray ionization mass spectrometry (native ESI MS) mostly in combination with time-of-flight (ToF) analyzers evolved as method of choice, yielding $\mathrm{M}_{\mathrm{W}}$ values of bionanoparticles after deconvolution of mass spectra. Such, the $\mathrm{M}_{\mathrm{W}}$ of dimorphic hepatitis B-based VLPs could be obtained already in 2008 [3]. In addition, several other VLPs or subviral particles $[4,5]$ up to a maximum $\mathrm{M}_{\mathrm{W}}$ of 17.9 MDa with charge state assignment [6] or employing cryodetection with matrix assisted laser desorption/ionization time-of-flight (MALDI TOF) MS [7] could be investigated. ESI with charge detection mass spectrometry (CDMS) [8, 9] even allowed detection of VLPs up to $26.8 \mathrm{MDa}$, employing bacteriophage P22 as model [10, 11]. Besides enabling the analysis of VLPs, also capsid binding to antibody fragments [12], pH-dependent VLP decomposition [13] or the investigation of VLP capsid assembly [14] was accessible via native ESI MS. However, none of these measurements can be carried out on standard commercial instruments. Employed mass spectrometers are usually customized in terms of, e.g., applied pressures, employed carrier gas or voltage settings, or pose completely new instrumental developments. In 2018, for instance, Dominguez-Medina and coworkers reported the analysis of bacteriophage T5 icosahedral capsids either in their empty VLP form $\left(\mathrm{M}_{\mathrm{W}} \sim 27 \mathrm{MDa}\right)$ or in their DNA-filled native form $\left(\mathrm{M}_{\mathrm{W}} \sim 108 \mathrm{MDa}\right)$ [15]. For these experiments, nanochemical resonators were employed [16, 17].

As alternative, $\mathrm{M}_{\mathrm{W}}$ determination can also be based on gasphase electrophoresis data employing a nano-electrospray gas-phase electrophoretic mobility molecular analyzer (native nES GEMMA also known as nES differential mobility analyzer, nES DMA) [18]. Bionanoparticles are electrosprayed from a volatile, aqueous electrolyte solution. Subsequently, droplets are dried. At the same time, charge equilibration occurs in a bipolar atmosphere induced by, e.g., an $\alpha$-particle emitter like ${ }^{210} \mathrm{Po}$, an alternating corona discharger or a soft $\mathrm{X}$ - ray tube $[19,20]$. Hence, singly charged particles are obtained (besides a majority of neutral objects), which are then separated according to electrophoretic principles in the gas phase at ambient pressure. A particle charge of one leads to bionanoparticle separation according only to the surface-dry particle size (electrophoretic mobility diameter, EMD) in a high laminar sheath flow of particle-free, dried air, and a tunable electric field. Variation of the field strength enables size separation of sample components. The obtained monodisperse aerosol is subsequently introduced to the detector unit of the instrument (ultrafine condensation particle counter, CPC), where bionanoparticles act as condensation nuclei in a supersaturated atmosphere of either n-butanol or water. Obtained droplets are counted as they pass a focused laser beam. Such an instrumentation has previously been employed for the analysis of liposomes [21, 22], exosomes [23], viruses [24-29], proteins and protein aggregates [30], polysaccharides [31-33], DNA [34], polymers [35-37], and nanoparticles in general [38-42]. Besides yielding information on analyte surface-dry particle size and size distribution, particle number concentration detection is possible in accordance with recommendations of the European Commission for characterization of nanoparticle material $\left(2011 / 696 / \mathrm{EU}\right.$ from October $18^{\text {th }}$, 2011). Furthermore, analytes can be size-selected for further analyses employing orthogonal methods for instance electron microscopy [43], atomic force microscopy [44], spectroscopic techniques $[45,46]$, or antibody-based nanoparticle recognition $[44,47]$. It is of note that LiquiScan ES, MacroIMS, and SMPS are synonyms of the same instrument found in literature.

Furthermore, as first demonstrated in great detail by Bacher and colleagues [48] for proteins, obtained EMD results can be related to particle $\mathrm{M}_{\mathrm{W}}$ values yielding a corresponding correlation. Hence, based on a protein EMD value, its $\mathrm{M}_{\mathrm{W}}$ can be calculated in good approximation. Similar approaches have been demonstrated, e.g., for intact viruses [4] and polysaccharides [32]. It is of note that for the latter two, the obtained $\mathrm{EMD} / \mathrm{M}_{\mathrm{W}}$ correlations deviated from the protein case. For instance for polysaccharides, it was reasoned that additional factors might influence the $\mathrm{EMD} / \mathrm{M}_{\mathrm{W}}$ correlation, inter alia particle shape, or insufficient characterization of applied, commercially available standards. Likewise, for elongated virus structures (tobacco mosaic virus), effects like bending of analytes due to surface effects of droplets generated during the $\mathrm{nES}$ process were observed [49].

In the current manuscript, we focus on nano-objects, namely VLPs, which are approximately spherical (icosahedral) and non-enveloped (empty protein shells). We asked ourselves, if a native $\mathrm{nES}$ GEMMA-based $\mathrm{EMD} / \mathrm{M}_{\mathrm{W}}$ correlation for VLPs is likewise differing from correlations described for other classes of analytes. In addition, we wanted to investigate if a corresponding $\mathrm{EMD} / \mathrm{M}_{\mathrm{W}}$ correlation will allow an approx. $\mathrm{M}_{\mathrm{W}}$ determination of this class of bionanoparticles with a 
relatively quick, cheap $(\sim 80.000 €)$, less challenging (in terms of sample quality) and easy to handle analytical setup in comparison to native ESI MS. Mind however, that a high accuracy $\mathrm{M}_{\mathrm{W}}$ determination of VLPs is only possible on the basis of MS-derived data. Hence, both methods have to be regarded as yielding complementary information in terms of analyte size and $\mathrm{M}_{\mathrm{W}}$, sample quality, and particle number concentration.

\section{Materials and methods}

Chemicals Ammonium acetate $\left(\mathrm{NH}_{4} \mathrm{OAc}, \geq 99.99 \%\right)$ and ammonium hydroxide (ACS reagent) were both purchased from Sigma-Aldrich (Steinheim, Germany).

Electrolyte $\mathrm{NH}_{4} \mathrm{OAc}, 40 \mathrm{mM}$ ammonium acetate at $\mathrm{pH} 7.0$ was used as electrolyte solution for desalting of VLPs and for sample dilution for nES GEMMA and ESI MS. Electrolyte solutions for CDMS measurements are detailed with corresponding experiments. $\mathrm{NH}_{4} \mathrm{OAc}$ solution was filtered $(0.2 \mu \mathrm{m}$ pore size syringe filters, Sartorius, Göttingen, Germany) prior application. Millipore (Billerica, MA, USA) grade water was employed $\left(18.2 \mathrm{M} \Omega \mathrm{cm}\right.$ resistivity at $\left.25^{\circ} \mathrm{C}\right)$.

Biological material Norovirus West Chester GI.1 VLPs (3 mg/ $\mathrm{mL}$ in PBS, $\mathrm{pH}$ 7.4) were produced in insect cells and kindly provided by Grant Hansman, Heidelberg, Germany, and CPMV VLPs $(4 \mathrm{mg} / \mathrm{mL}$ in $10 \mathrm{mM}$ sodium phosphate, $\mathrm{pH}$ 7.0) were from John Innes Centre (kindly provided by George Lomonossoff, Norwich, UK). Bacteriophage P22 VLPs $(2 \mathrm{mg} / \mathrm{mL}$ in $50 \mathrm{mM}$ sodium phosphate, $\mathrm{pH} 7.0$ including $100 \mathrm{mM}$ sodium chloride and $200 \mathrm{ppm}$ sodium azide) were obtained from Indiana University Bloomington (Bloomington, IN, USA), bacteriophage T5 VLPs $(0.3 \mathrm{mg} /$ $\mathrm{mL}$, i.e., $7 \times 10^{12}$ empty capsids $/ \mathrm{mL}$ in PBS) from the Institute for Integrative Biology of the Cell (I2BC), Gif-surYvette, France). Human papillomavirus type 16 (HPV16, $0.3 \mathrm{mg} / \mathrm{mL}$ in PBS additionally including $625 \mathrm{mM}$ sodium chloride, $0.9 \mathrm{mM}$ calcium chloride, $0.5 \mathrm{mM}$ magnesium chloride, and $2.1 \mathrm{mM}$ potassium chloride) VLPs were prepared from mammalian cells as previously described [50].

Instrumentation Gas-phase electrophoresis was performed on two setups: a nES GEMMA instrument (TSI Inc., Shoreview, MN, USA) consisting of a nES aerosol generator (model 3480 ) including a ${ }^{210}$ Po $\alpha$-particle source, an electrostatic classifier (model 3080) with a nano-differential mobility analyzer (nDMA) and an n-butanol-based ultrafine condensation particle counter (model 3025A or 3776C) was applied as instrument A. Instrument B consisted of a model $3482 \mathrm{nES}$ aerosol generator including a soft X-ray source, an electrostatic classifier (model 3082) and a water-based ultrafine condensation particle counter (model 3788). Twenty-five $\mu \mathrm{m}$ inner diameter polyimide coated fused silica capillaries (Polymicro, obtained via Optronis, Kehl, Germany) with in-house made tips [51] were employed to transfer analytes from the liquid to the gas phase. Settings for a stable Taylor cone at the nES tip were chosen, typically around $2 \mathrm{kV}$ voltage resulting in approx. $-375 \mathrm{nA}$ current, 0.1 liters per minute $(\mathrm{Lpm}) \mathrm{CO}_{2}$ (Messer, Gumpoldskirchen, Austria) and 1.0 Lpm filtered, dried ambient air. Four pounds per square inch differential (psid, approx. $27.6 \mathrm{kPa}$ ) were applied to additionally move the sample through the capillary. Fifteen Lpm sheath flow filtered ambient air was used to size-separate VLPs in an EMD range from 2 to $65 \mathrm{~nm}$. The corresponding EMD size range was scanned for $120 \mathrm{~s}$. Subsequently, the applied voltage was adjusted to starting values within a 30-s timeframe. Seven datasets (raw data obtained from instrument software, MacroIMS manager v2.0.1.0) were combined via their median to yield a corresponding spectrum. Lastly, Gaussian peaks were fitted to spectra via Origin software (OriginPro v9.1.0) to obtain EMD values.

HPV16 VLPs cannot be produced in high yields. Due to the resulting low VLP concentration, samples were only analyzed between 30 and $65 \mathrm{~nm}$ EMD to increase the scanning time in this range. In addition, a $40 \mu \mathrm{m}$ inner diameter capillary was employed to reduce the surface to volume ratio and hence the probability of analyte loss due to VLP interaction with the fused silica material of the nES capillary. This resulted in significantly higher particle numbers detected per channel and hence a discernible VLP peak.

For CPMV and P22 VLPs, native MS was performed on a Q-Tof 2 instrument (Waters, Manchester, UK, and MS Vision, Almere, the Netherlands) modified for high mass experiments [52, 53] and calibrated with cesium iodide. A nano-ESI source in positive ion mode with a source pressure of 10 mbar was used. Capillaries were produced in-house. Borosilicate glass tubes (inner diameter $0.68 \mathrm{~mm}$, outer diameter $1.2 \mathrm{~mm}$ with filament; World Precision Instruments, Sarasota, FL, USA) were pulled using a two-step program in a micropipette puller (model P-1000 from Sutter Instruments, Novato, CA, USA) with a squared box filament $(2.5 \times 2.5 \mathrm{~mm})$. Subsequently, the capillaries were gold-coated using a sputter coater (Quorum Technologies, East Sussex, UK, $40 \mathrm{~mA}, 200 \mathrm{~s}$, tooling factor of 2.3 and end bleed vacuum of $8 \times$ $10^{-2}$ mbar argon) and opened directly on the sample cone of the mass spectrometer. Voltages of $1.45-1.65 \mathrm{kV}$ and 145-155 V were applied to the capillary and cone, respectively. Xenon (purity 5.0) was used as collision gas at a pressure of 1.7-2.0 $\times 10^{-2}$ mbar to improve the transmission of large ions [53]. Collision energies were ramped from 10 to $400 \mathrm{~V}$. MS profile and repetition frequency of the pusher pulse were adjusted to high mass range. Mass spectra were analyzed using MassLynx (Waters, Manchester, UK). 
Mass spectra of norovirus West Chester VLPs were obtained using a home-built ESI CDMS system, described in detail elsewhere [54]. Briefly, CDMS is a single particle MS technique, which retrieves $\mathrm{m} / \mathrm{z}$ and $z$ for each ion allowing direct mass determination from a charge conducting cylinder functioning also as electrostatic ion trap. Hence, masses of large, heterogeneous biological complexes can be measured. An automated nano-ESI source (Advion, Ithaca, NY, USA) was used to generate ions with a capillary voltage of $1.7 \mathrm{kV}$. The ions then enter a heated metal capillary and are transmitted using various ion optics to a dual hemispherical deflection energy analyzer which selects ions with energies centered on $100 \mathrm{eV} / z$. These ions then enter a modified cone trap. Here, trapped ions oscillate back and forth in a charge detection cylinder for $100 \mathrm{~ms}$. Mass spectra were generated by binning of the single ion masses. Spectra were subsequently analyzed by fitting Gaussian peaks with Origin software (OriginPro 2016).

Sample preparation In order to enable native $\mathrm{nES}$-based analysis of VLPs, employed storage buffers (often including additional salt components or stabilizing agents) had to be replaced by a volatile electrolyte solution. Else, these additional sample components were shown to lead to an increased peak heterogeneity of the analytes of interest and, in nES GEMMA, an elevated baseline resulting from clustering of small, nonvolatile molecules during the $\mathrm{nES}$ process [55]. As in previous studies, we opted for ammonium acetate and carried out removal of small, buffer-associated sample components via spin filtration [42] employing $10 \mathrm{kDa} \mathrm{M}$ cutoff filters (Vivaspinpolyethersulfone membrane, Vivacon-regenerated cellulose membrane-both from Sartorius or centrifugal filterspolyethersulfone membrane, VWR, Vienna, Austria). Between 3 and 5 filtration steps were necessary to remove non-volatile additional sample components. Sample concentration for measurements was typically well below $1 \mathrm{mg} / \mathrm{mL}$ protein content (based on originally determined values and sample dilution).

\section{Results and discussion}

It was the aim of our investigation to analyze VLP material with gas-phase electrophoresis on a native nES GEMMA instrument and to compare results with data obtained from native ESI MS and from literature. We intended to setup an EMD/M $\mathrm{M}_{\mathrm{W}}$ correlation for VLPs to allow for future VLP $\mathrm{M}_{\mathrm{W}}$ determination based on gas-phase electrophoresis directed towards analysis of samples not applicable to native ESI ToF MS.

Native nES GEMMA analysis of VLPs In previous work, we had already described the analysis of VLP or VLP-like material based on hepatitis B virus capsids (HBV) with two icosahedral symmetries [12] and subviral particles of a human rhinovirus serotype (HRV-A2) [4]. We now turned to further VLP material and analyzed bionanoparticles derived from cowpea mosaic virus (CPMV), a norovirus strain and particles from bacteriophage P22 and T5 via gas-phase electrophoresis. Figure 1 depicts corresponding native nES GEMMA spectra. An overview of investigated VLPs and resulting EMD values are listed in Table 1 . In order to exclude the possibility of unspecific aggregation of sample components, VLPs were electrosprayed from samples diluted to at least three different concentrations. Unspecific aggregation of components was excluded, if peaks remained at identical EMD values for all investigated dilutions.

Besides information on the surface-dry VLP size and an approximation on the bionanoparticle number concentration, two other pieces of information could be gathered from native nES GEMMA spectra. (i) Especially for norovirus West Chester VLPs (Fig. 1b), detection of material below $10 \mathrm{~nm}$ EMD hinted the presence of free proteins. Pogan et al. [13] showed that these particles already disassemble at neutral $\mathrm{pH}$ and low ionic strengths, which is in line with our results. Moreover, general particle rupture in the nES process is unlikely, as such peaks were only recorded for norovirus West Chester VLPs. (ii) Especially for bacteriophage P22-based VLPs (Fig. 1c) several additional species with significantly lower abundance than the main VLP peak were detected (e.g., at 34 or $45 \mathrm{~nm}$ EMD). If these peaks correspond to species simply carrying a higher number of charges from insufficient charge equilibration in the bipolar atmosphere of the nES unit or are analytes of biological relevance (e.g., capsids losing subunits) cannot be determined based on obtained native nES GEMMA results alone. However, ESI ToF MS also showed at least one additional species, which indicates that the observed peaks correspond to different assemblies present in solution (Fig. 2).

Native ESI MS analysis of VLPs Next to targeting these VLP analytes via native $\mathrm{nES}$ GEMMA, we also applied native ESI MS in VLP characterization. Employing Q-ToF instruments, challenges of VLP $\mathrm{M}_{\mathrm{W}}$ determination in native ESI MS become obvious. For the same samples as with native nES GEMMA, clear peaks were obtained via native ESI ToF MS (Fig. 2). However, the lack of charge state separation hampered exact mass determination. Common sources for lack of resolution are intrinsic VLP heterogeneity mostly on protein level, e.g., the presence of truncated protein or sequence variants, or simply size resulting in overlapping charge states. As was shown in a previous study, the problems in charge state resolution can be instrument, but as well analyte derived [3]. Furthermore, incomplete desolvation can additionally cause peak broadening, which influences native ESI ToF MS to a higher extent than gas-phase electrophoresis. Nevertheless, 
Fig. 1 nES GEMMA data for VLPs: CPMV (a), norovirus West Chester (b), bacteriophage P22 (c), and bacteriophage T5 capsids (d). All VLPs are shown in three different dilutions of obtained material after solution exchange to $40 \mathrm{mM} \mathrm{NH}_{4} \mathrm{OAc}, \mathrm{pH} 7.0$ employing $10 \mathrm{kDa} \mathrm{M}_{\mathrm{W}}$ cutoff membrane filters. (Typically, overall dilutions were in the range of $1: 10$ to $1: 250[v: v]$ of the original VLP stock solutions resulting from solution exchange and sample dilution steps)
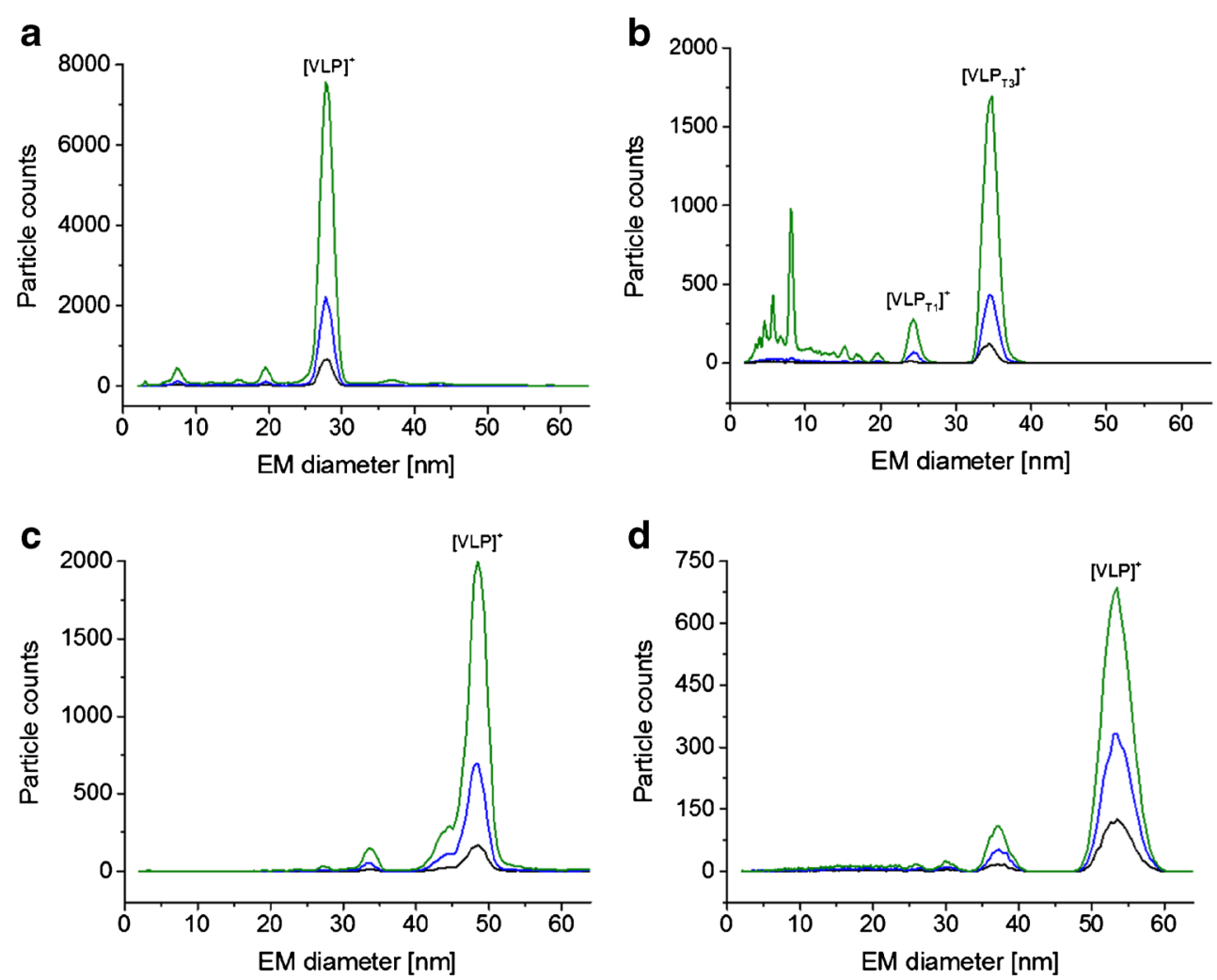

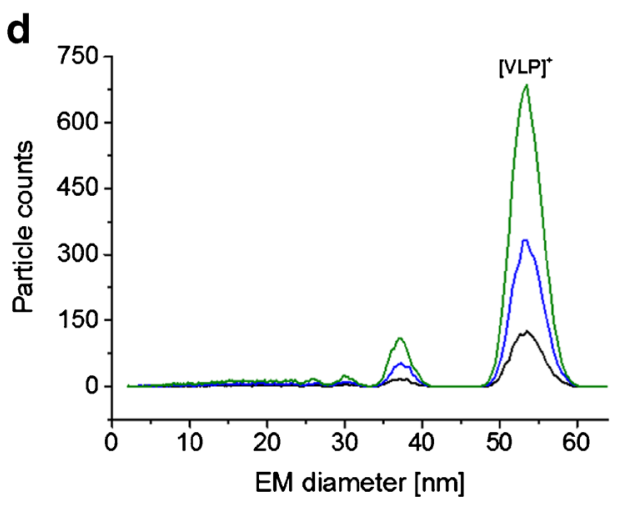

using an experimentally derived equation [57], also in such cases, the $\mathrm{M}_{\mathrm{W}}$ can be estimated from the obtained $\mathrm{m} / \mathrm{z}$ values. Taking for instance $\mathrm{m} / \mathrm{z}$ of 22,600 for CPMV into consideration, a $\mathrm{M}_{\mathrm{W}}$ of $3107 \mathrm{kDa}$ is obtained, for bacteriophage $\mathrm{P} 22$, an $m / z$ of 55,600 yields a $\mathrm{M}_{\mathrm{W}}$ of $18,807 \mathrm{kDa}$. Both $\mathrm{M}_{\mathrm{W}}$ values are in the same range as data found in literature (see Table 1). In general, the spectra show that the number of different observed sizes is in line with the nES GEMMA results. Moreover, the norovirus VLPs were also analyzed on an ESI CDMS instrument to provide $\mathrm{M}_{\mathrm{W}}$ values without the need for charge state resolution and obtain more values for the correlation (Electronic Supplementary Material (ESM) Fig. S1). Additionally, application of an Orbitrap instrument with higher resolution might help to resolve charge states in a future study.

Combining native $n E S$ GEMMA and native ESI MS data yields an EMD/M $\mathrm{M}_{\mathrm{W}}$ correlation for VLPs Based on our analyses of VLP material via native nES GEMMA and accurate mass values from native ESI MS including literature values (given in Table 1), we set up a corresponding EMD/ $\mathrm{M}_{\mathrm{W}}$ correlation: $\mathrm{y}\left[\mathrm{M}_{\mathrm{W}}\right.$ in $\left.\mathrm{kDa}\right]=0.7601$ [EMD in $\left.\mathrm{nm}\right]^{2.6319}$ (Fig. 3). Notably, this deviates from a correlation for proteins as was the case for filled virions [32]. Hence, a basic knowledge concerning the analyte class prior EMD-based $\mathrm{M}_{\mathrm{W}}$ calculation (but not for gas-phase electrophoresis itself) is necessary.

Table 1 Overview on investigated VLP material as well as data taken from literature as indicated

\begin{tabular}{|c|c|c|c|c|c|c|c|}
\hline \multirow[b]{2}{*}{1} & \multirow{2}{*}{$\begin{array}{l}\text { VLP } \\
\text { Norovirus West Chester T1 VLP }\end{array}$} & \multicolumn{2}{|c|}{ EM diameter (nm) } & \multirow{2}{*}{$\begin{array}{l}\text { Based on } \\
-\end{array}$} & \multicolumn{2}{|c|}{$\mathrm{M}_{\mathrm{W}}(\mathrm{kDa})$} & \multirow{2}{*}{$\begin{array}{c}\text { Based or } \\
\text { CDMS }\end{array}$} \\
\hline & & 24.22 & \pm 0.21 & & 3320 & \pm 30 & \\
\hline 2 & Hepatitis B virus (HBV) T3 VLP & 24.22 & \pm 0.40 & {$[12]$} & 3004 & \pm 3 & MS [12] \\
\hline 3 & Hepatitis B virus (HBV) T4 VLP & 26.84 & \pm 0.44 & {$[12]$} & 4006 & \pm 3 & MS [12] \\
\hline 4 & Cowpea mosaic virus (CPMV) VLP & 27.88 & \pm 0.04 & - & 3940 & \pm n.a. & {$[56]$} \\
\hline 5 & Subviral B particle of human rhinovirus 2 & 28.68 & \pm 0.07 & {$[4]$} & 5210 & \pm 2 & MS [4] \\
\hline 6 & Norovirus West Chester T3 VLP & 34.47 & \pm 0.15 & - & 10,260 & \pm 40 & $C D M S$ \\
\hline 7 & Bacteriophage P22 VLP & 48.44 & \pm 0.12 & - & 19,840 & \pm n.a. & MS [11] \\
\hline 8 & Bacteriophage T5 VLP & 53.45 & \pm 0.09 & - & 27,200 & \pm 2300 & MS [15] \\
\hline
\end{tabular}

New data is presented in italics. An exemplary CDMS spectrum of investigated VLPs is shown in the ESM (Fig. S1). At least $N=3$ technical replicates were used per EMD value. Errors provided are standard deviations 

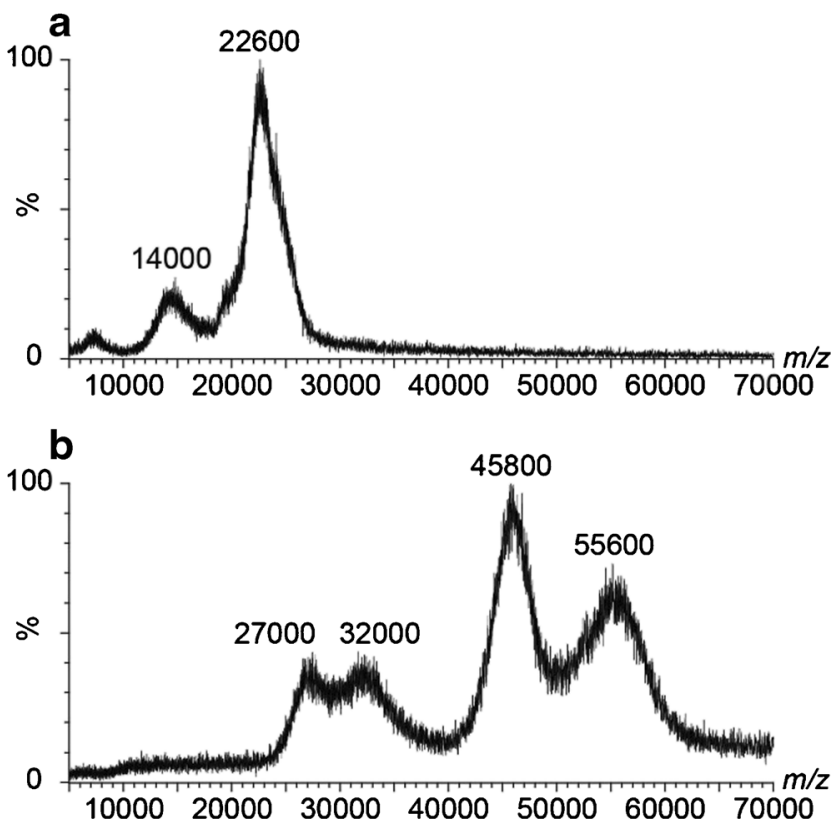

Fig. 2 QTOF native ESI MS data for VLPs: CPMV at $50 \mathrm{~V}$ collision energy (a) and bacteriophage P22 at $100 \mathrm{~V}$ collision energy (b) are shown. Although in both cases signals are detected, analyte heterogeneity precluded charge state resolution. $\mathrm{m} / \mathrm{z}$ values at peak apices are given. VLPs were exchanged to $40 \mathrm{mM} \mathrm{NH} \mathrm{N}_{4} \mathrm{OAc}$, $\mathrm{pH} 7.0$, using $10 \mathrm{kDa} \mathrm{M} \mathrm{W}_{\mathrm{W}}$ cutoff filters. Peaks at 14,000, 27,000, and 32,000 m/z, may represent metastable ions

A collapse of VLP particles during gas-phase electrophoresis upon stripping of solvent molecules from their interior seems highly unlikely as AFM and dot-blot analyses of a vaccine VLP demonstrated particle integrity after gas-phase electrophoresis [44]. Instead, due to protein analyte inherent $\mathrm{M}_{\mathrm{W}}$ limitations, especially a direct comparison of a protein correlation with an EMD/ $\mathrm{M}_{\mathrm{W}}$ correlation for VLPs is to date not feasible. Simply because VLPs are analyzed in an EMD/ $\mathrm{M}_{\mathrm{W}}$ range, in which pure protein complexes (in a nonaggregated or structured form) rarely exist, the extrapolation

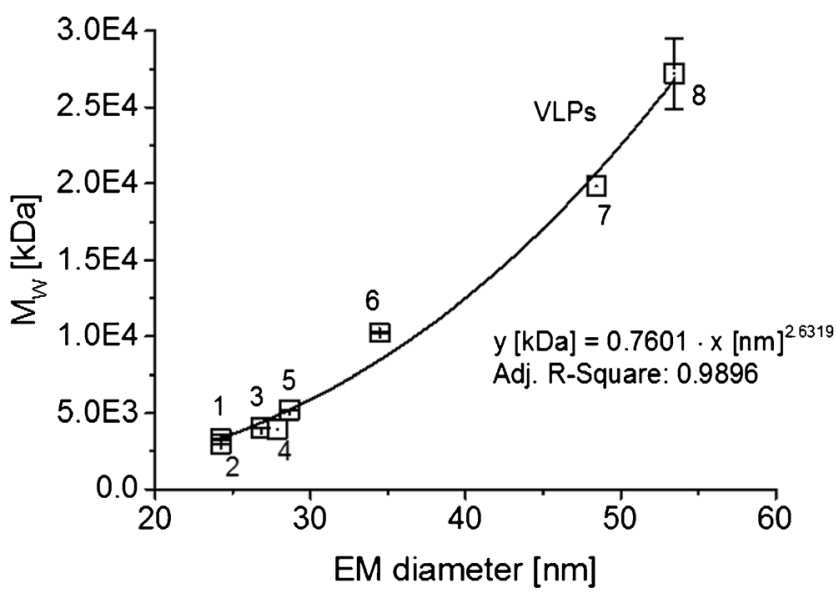

Fig. 3 nES GEMMA and MS data can be related to yield an EMD/M $\mathrm{M}_{\mathrm{W}}$ correlation valid for VLPs. The numbering of data points correlates to Table 1 of the protein EMD/ $\mathrm{M}_{\mathrm{W}}$ correlation to larger EMD and $\mathrm{M}_{\mathrm{W}}$ values has to be taken with extreme caution. It is of note that the largest protein analyzed in [32] was the octamer of $\beta$ galactosidase with an EMD of $16.83 \mathrm{~nm}$ and a $\mathrm{M}_{\mathrm{W}}$ of $931.28 \mathrm{kDa}$.

In contrast, the VLP-based EMD/M $\mathrm{M}_{\mathrm{W}}$ correlation is based on data points for larger EMD/M $\mathrm{M}_{\mathrm{W}}$ values. VLPs with low $\mathrm{EMD} / \mathrm{M}_{\mathrm{W}}$ value are not reasonable as the proteinaceous sphere has to be of a certain lower size limit (around $20 \mathrm{~nm}$ ) in order to allow for genome encapsulation within the capsid. Therefore, there is poor overlap between pure protein complex and VLP curves. Extrapolation of either the protein correlation to large or the VLP correlation to lower EMD/M $\mathrm{M}_{\mathrm{W}}$ values is problematic. Hence, we advise against taking one single $\mathrm{EMD} / \mathrm{M}_{\mathrm{W}}$ correlation for all investigated analyte classes in order to calculate $\mathrm{M}_{\mathrm{W}}$ values based on a particle EMD.

$E M D / M_{W}$ correlations on different native $n E S$ GEMMA instruments As it was our intention to setup an $\mathrm{EMD} / \mathrm{M}_{\mathrm{W}}$ correlation for VLPs applicable to as many as possible corresponding native nES GEMMA instrumentations, we asked ourselves, if obtained results can be ported between setups. Laschober and colleagues already reported in 2007 differences of up to $15 \%$ in obtained EMD values for globular proteins up to $660 \mathrm{kDa}$ [58]. Especially slight variations in nDMA geometries, length values of connecting tubes between instrument parts or differences in sheath flow values may lead to deviations observed between instruments. Therefore, we analyzed a set of analytes on another gas-phase electrophoretic setup besides our standard native nES GEMMA (instrument A). This instrument corresponded to a next-generation setup with differences in the geometry of the nES source and a soft X-ray source for charge equilibration (instrument B). Detection on the latter instrumentation was carried out on a water-based CPC. We

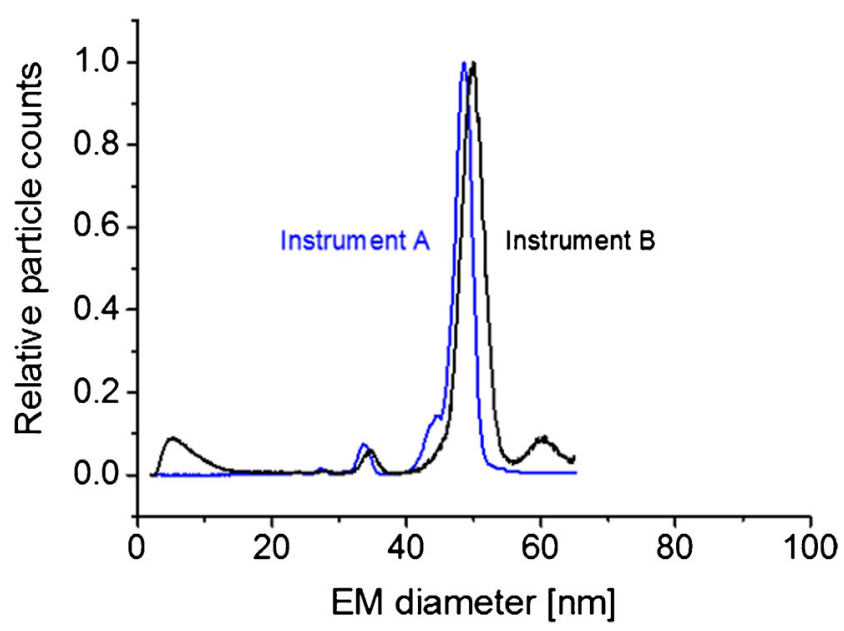

Fig. 4 Comparing gas-phase electrophoresis data obtained on two instrument generations. As shown for bacteriophage P22, a significant shift in obtained EMD values on both instruments is found. Corresponding EMD data is found in Table 2 
Table 2 Comparison of averaged EMD values obtained on several gas-phase electrophoretic instrumentations

\begin{tabular}{|c|c|c|c|c|c|c|c|}
\hline \multirow[t]{2}{*}{ Analyte } & & \multirow{2}{*}{$\begin{array}{l}\text { MW } \\
(\mathrm{kDa})\end{array}$} & \multicolumn{3}{|c|}{ Instrument A } & \multicolumn{2}{|c|}{ Instrument B } \\
\hline & & & $\begin{array}{l}\text { EMD } \\
(\mathrm{nm})\end{array}$ & STDEV & $\begin{array}{l}\text { (\%) value } \\
\text { instrument B }\end{array}$ & $\begin{array}{l}\text { EMD } \\
(\mathrm{nm})\end{array}$ & STDEV \\
\hline $\operatorname{IgG}$ & M & 147.27 & 9.03 & 0.10 & 95.19 & 9.49 & 0.04 \\
\hline $\operatorname{IgG}$ & $\mathrm{D}$ & 294.54 & 11.26 & 0.10 & 95.58 & 11.78 & 0.04 \\
\hline$\beta$-Gal & M & 116.41 & 8.33 & 0.11 & 95.76 & 8.70 & 0.03 \\
\hline$\beta-G a l$ & $\mathrm{D}$ & 232.82 & 10.57 & 0.11 & 95.52 & 11.07 & 0.02 \\
\hline Dextran 150 & M & 147.6 & 8.17 & 0.15 & 98.67 & 8.28 & 0.01 \\
\hline Dextran 670 & M & 667.8 & 10.05 & 0.41 & 92.88 & 10.82 & 0.12 \\
\hline Oat $\beta$ glucan 80 & M & 81 & 7.12 & 0.04 & 93.81 & 7.59 & 0.03 \\
\hline $\begin{array}{c}\text { Oat } \beta \text { glucan } \\
1500\end{array}$ & M & 1508 & 7.71 & 0.15 & 94.83 & 8.13 & 0.04 \\
\hline CPMV VLP & M & 3940 & 27.88 & 0.04 & 99.32 & 28.07 & 0.07 \\
\hline P22 VLP & M & 19,840 & 48.44 & 0.12 & 97.21 & 49.83 & 0.07 \\
\hline
\end{tabular}

At least $N=3$ measurements were considered per EMD value. $\mathrm{M}_{\mathrm{W}}$ values and data for instrument A either taken from [32] or Table 1. $M$ monomer, $D$ dimer; errors provided are standard deviations opted for immunoglobulin $\mathrm{G}$ (IgG), $\beta$-galactosidase $(\beta$-Gal), several polysaccharides (dextrans and oat $\beta$ glucans), CPMV VLP, and bacteriophage P22 VLP as analytes.

Resulting spectra from gas-phase electrophoresis carried out on the two instrumentations are depicted in Fig. 4 as exemplified by P22 VLPs. Corresponding data for all analytes is given in Table 2. As can be seen, indeed slight differences between instrumentations were detected. For instance, the EMD of investigated proteins deviated on average by $4.5 \%$ at the peak apex between our standard instrumentation (instrument A) and the next-generation setup (instrument B). Less variation was found for VLPs, more for polysaccharides. Based on this data, we strongly suggest calibration of each instrument for corresponding EMD-based $\mathrm{M}_{\mathrm{W}}$ calculation: Instrument specific parameters have to be regarded in order to obtain reliable EMD-based $\mathrm{M}_{\mathrm{W}}$

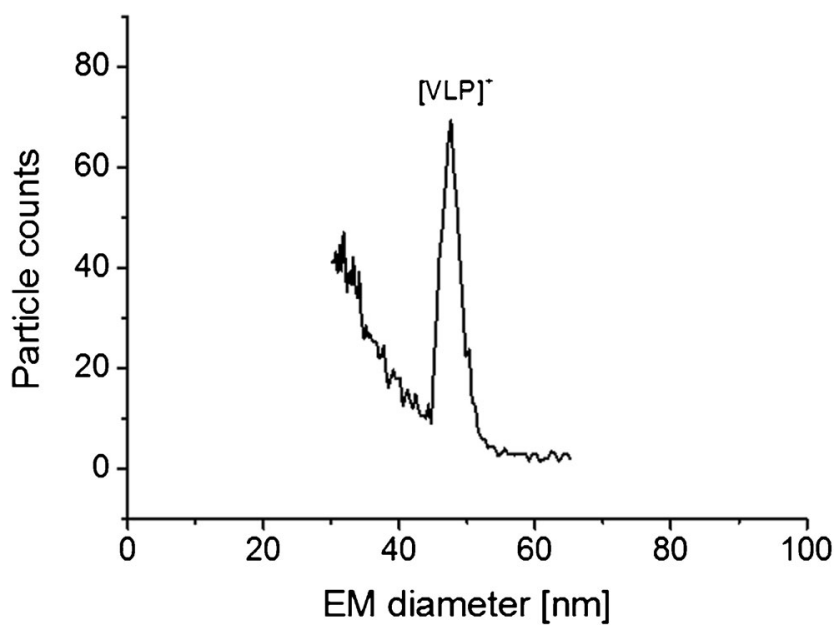

Fig. 5 nES GEMMA yields a peak for HPV16-based VLPs allowing its subsequent $\mathrm{M}_{\mathrm{W}}$ determination based on the correlation presented in Fig. 3. The calculated $\mathrm{M}_{\mathrm{W}}(19,975 \mathrm{kDa})$ is in good accordance with the theoretically expected $\mathrm{M}_{\mathrm{W}}$ value (20,260 $\mathrm{kDa}$, based on VLP stoichiometry and database $\mathrm{M}_{\mathrm{W}}$ values for individual viral proteins) values via gas-phase electrophoresis. A simple porting of EMD/ $\mathrm{M}_{\mathrm{W}}$ correlations between instrumentations without considering a corresponding deviation would lead to significant systematic errors in EMD-based particle $\mathrm{M}_{\mathrm{W}}$ calculation.

Application of the developed EMD/ $\mathrm{M}_{\mathrm{W}}$ correlation in VLP research, an example Following the setup of our EMD/M $\mathrm{M}_{\mathrm{W}}$ correlation for VLPs, we turned to another VLP based on HPV16, for which no native MS data was obtained so far. We carried out our analyses on our standard instrumentation (instrument A). Employing native nES GEMMA, we could obtain a peak at $47.78 \pm 0.29 \mathrm{~nm}$ EM diameter $(N=4$ measurements, Fig. 5). Subsequently, we employed our EMD/M $\mathrm{M}_{\mathrm{W}}$ correlation for the calculation of the VLP $\mathrm{M}_{\mathrm{W}}$. A result of $19,975 \mathrm{kDa}$ is in good accordance with the expected value of $20,260 \mathrm{kDa}$ (based on 72 pentamers of coat protein L1, Uniprot data, P03101, retrieved on January $17^{\text {th }}, 2019$ ); the deviation is in fact below 1.5\%. Reasons for this deviation could be inter alia (i) a still relatively low number of data points available for the VLP EMD/M $\mathrm{M}_{\mathrm{W}}$ correlation, (ii) the shape, surface texture, or tightness of the proteinaceous shell itself, (iii) additional material encapsulated within VLPs, or (iv) differences between VLP material measured via native nES GEMMA and material described in the database. Nevertheless, employing HPV16 as an exemplary VLP bionanoparticle, we were able to demonstrate the applicability of native $n E S$ GEMMA-based $\mathrm{M}_{\mathrm{W}}$ determination of VLP analytes.

\section{Concluding remarks}

For pharmaceutical applications as pointed out above, the thorough characterization of VLPs in terms of particle size, 
$\mathrm{M}_{\mathrm{W}}$, sample, and analyte heterogeneity and particle numberbased concentration is a necessary prerequisite. In general, it can be seen that ESI MS, whether from ToF or CDMS instruments, is in good agreement with nES GEMMA in terms of species detected. Hence, ESI MS results can be used to interpret nES GEMMA data of unknown samples. However, although native ESI ToF MS is unrivaled in VLP $\mathrm{M}_{\mathrm{W}}$ determination, it often experiences problems due to sample specific problems, like heterogeneity or low particle numbers. Even though ESI CDMS is not suffering from sample heterogeneity, it is slow, requiring several hours per mass spectrum, and the home-built instrumentation is not widely accessible. nES GEMMA on the other hand is less prone to the mentioned sample inherent characteristics and is relatively cheap facilitating wide application. Analytes are separated according to electrophoretic principles in the gas-phase at ambient pressure based on their size yielding particle number-based concentrations. As has already been shown for other analyte classes, a subsequent correlation between the nES GEMMA-derived EMD and the particle $\mathrm{M}_{\mathrm{W}}$ allows (bio-)nanoparticle $\mathrm{M}_{\mathrm{W}}$ calculation in good approximation. We now focused on spherical VLPs and analyzed a variety of these bionanoparticles to setup an $\mathrm{EMD} / \mathrm{M}_{\mathrm{W}}$ correlation, which we found significantly different from correlations known for, e.g., proteins or intact virus particles. As such, it is crucial to know the nature of samples prior to $\mathrm{M}_{\mathrm{W}}$ determination. As demonstrated, application of this correlation allowed us to calculate the $\mathrm{M}_{\mathrm{W}}$ of a VLP, for which native ESI MS data is not available to date. Especially through the combination of both methods, nES GEMMA and native ESI MS, as exemplified here, a thorough VLP characterization will be feasible in the future.

Acknowledgments Open access funding provided by TU Wien (TUW). VUW acknowledges funding of the Austrian Theodor Körner Fonds. VUW and RP both acknowledge funding of COST Action BM1403 Native Mass Spectrometry and Related Methods for Structural Biology. The Heinrich-Pette-Institute, Leibniz Institute for Experimental Virology is supported by the Freie und Hansestadt Hamburg and the Bundesministerium für Gesundheit (BMG). CU acknowledges funding from the Leibniz Association through SAW-2014-HPI-4 grant. RP acknowledges funding from EU Horizon 2020 project VIRUSCAN 731868 and thanks MINGS. CU, RP, DP and MS further thank the DFG FOR2327 Virocarb for support. We thank Grant Hansman and George Lomonossoff for providing VLPs. ES was supported by the Graduate Training Program in Quantitative and Chemical Biology under Award T32 GM109825 and Indiana University.

Author contributions Initial idea: VUW, GA; nES GEMMA measurements: VUW, RP, SZ; MS measurements: RP, KB, NL; sample preparation: PB, DP, MS, ES; data interpretation: VUW, RP, CU, GA; instrumentation: GA, CU, MFJ; funding: GA, CU, VUW; scientific guidance: GA, CU, VUW; organization: VUW; all authors contributed to the manuscript.

\section{Compliance with ethical standards}

Conflict of interest The authors declare that they have no conflict of interest.

Open Access This article is distributed under the terms of the Creative Commons Attribution 4.0 International License (http:// creativecommons.org/licenses/by/4.0/), which permits unrestricted use, distribution, and reproduction in any medium, provided you give appropriate credit to the original author(s) and the source, provide a link to the Creative Commons license, and indicate if changes were made.

\section{References}

1. Sieben C, Kappel C, Zhu R, Wozniak A, Rankl C, Hinterdorfer P, et al. Influenza virus binds its host cell using multiple dynamic interactions. P Natl Acad Sci USA. 2012;109(34):13626-31.

2. Zeltins A. Construction and characterization of virus-like particles: a review. Mol Biotechnol. 2013;53(1):92-107.

3. Uetrecht C, Versluis C, Watts NR, Roos WH, Wuite GJ, Wingfield PT, et al. High-resolution mass spectrometry of viral assemblies: molecular composition and stability of dimorphic hepatitis B virus capsids. Proc Natl Acad Sci U S A. 2008;105(27):9216-20.

4. Weiss VU, Bereszcazk JZ, Havlik M, Kallinger P, Gosler I, Kumar $\mathrm{M}$, et al. Analysis of a common cold virus and its subviral particles by gas-phase electrophoretic mobility molecular analysis and native mass spectrometry. Anal Chem. 2015;87(17):8709-17.

5. Snijder J, van de Waterbeemd M, Damoc E, Denisov E, Grinfeld D, Bennett A, et al. Defining the stoichiometry and cargo load of viral and bacterial nanoparticles by Orbitrap mass spectrometry. J Am Chem Soc. 2014;136(20):7295-9.

6. Snijder J, Rose RJ, Veesler D, Johnson JE, Heck AJR. Studying 18 $\mathrm{MDa}$ virus assemblies with native mass spectrometry. Angew Chem Int Edit. 2013;52(14):4020-3.

7. Sipe DM, Ozdemir A, Firek B, Hendrix RW, Bier ME. Analysis of viral CapsidHK97 via cryodetection MALDI TOF in the megadalton mass range. In: 56th ASMS Conference on Mass Spectrometry and Allied Topics. June 1st-5th, 2008; Denver, CO, USA(\# 571).

8. Keifer DZ, Pierson EE, Jarrold MF. Charge detection mass spectrometry: weighing heavier things. Analyst. 2017;142(10):1654-71.

9. Keifer DZ, Motwani T, Teschke CM, Jarrold MF. Measurement of the accurate mass of a $50 \mathrm{MDa}$ infectious virus. Rapid Commun Mass Spectrom. 2016;30(17):1957-62.

10. Keifer DZ, Motwani T, Teschke CM, Jarrold MF. Acquiring structural information on virus particles with charge detection mass spectrometry. J Am Soc Mass Spectrom. 2016;27(6):1028-36.

11. Keifer DZ, Pierson EE, Hogan JA, Bedwell GJ, Prevelige PE, Jarrold MF. Charge detection mass spectrometry of bacteriophage P22 procapsid distributions above $20 \mathrm{MDa}$. Rapid Commun Mass Spectrom. 2014;28(5):483-8.

12. Bereszczak JZ, Havlik M, Weiss VU, Marchetti-Deschmann M, van Duijn E, Watts NR, et al. Sizing up large protein complexes by electrospray ionisation-based electrophoretic mobility and native mass spectrometry: morphology selective binding of Fabs to hepatitis B virus capsids. Anal Bioanal Chem. 2014;406(5):143746. 
13. Pogan R, Schneider C, Reimer R, Hansman G, Uetrecht C. Norovirus-like VP1 particles exhibit isolate dependent stability profiles. J Phys Condens Matter. 2018;30(6):064006.

14. Shoemaker GK, van Duijn E, Crawford SE, Uetrecht C, Baclayon $\mathrm{M}$, Roos WH, et al. Norwalk virus assembly and stability monitored by mass spectrometry. Mol Cell Proteomics. 2010;9(8):1742-51.

15. Dominguez-Medina S, Fostner S, Defoort M, Sansa M, Stark AK, Halim MA, et al. Neutral mass spectrometry of virus capsids above 100 megadaltons with nanomechanical resonators. Science. 2018;362(6417):918-22.

16. Naik AK, Hanay MS, Hiebert WK, Feng XL, Roukes ML. Towards single-molecule nanomechanical mass spectrometry. Nat Nanotechnol. 2009;4(7):445-50.

17. Malvar O, Ruz JJ, Kosaka PM, Dominguez CM, Gil-Santos E, Calleja M, et al. Mass and stiffness spectrometry of nanoparticles and whole intact bacteria by multimode nanomechanical resonators. Nat Commun. 2016;7:13452.

18. Kaufman SL, Skogen JW, Dorman FD, Zarrin F, Lewis KC. Macromolecule analysis based on electrophoretic mobility in air: globular proteins. Anal Chem. 1996;68(11):1895-904.

19. Kallinger P, Szymanski WW. Experimental determination of the steady-state charging probabilities and particle size conservation in non-radioactive and radioactive bipolar aerosol chargers in the size range of 5-40 nm. J Nanopart Res. 2015;17(4):171.

20. Allmaier G, Weiss VU, Engel NY, Marchetti-Deschmann M, Szymanski WW. Soft X-ray radiation applied in the analysis of intact viruses and antibodies by means of nano electrospray differential mobility analysis. In: Banoub JH, Caprioli RM, editors. Molecular technologies for detection of chemical and biological agents. Dordrecht: Springer Netherlands; 2017. p. 149-57.

21. Epstein H, Afergan E, Moise T, Richter Y, Rudich Y, Golomb G. Number-concentration of nanoparticles in liposomal and polymeric multiparticulate preparations: empirical and calculation methods. Biomaterials. 2006;27(4):651-9.

22. Weiss VU, Urey C, Gondikas A, Golesne M, Friedbacher G, von der Kammer F, et al. Nano electrospray gas-phase electrophoretic mobility molecular analysis (nES GEMMA) of liposomes: applicability of the technique for nano vesicle batch control. Analyst. 2016;141(21):6042-50.

23. Chernyshev VS, Rachamadugu R, Tseng YH, Belnap DM, Jia YL, Branch KJ, et al. Size and shape characterization of hydrated and desiccated exosomes. Anal Bioanal Chem. 2015;407(12):3285-301.

24. Hogan CJ Jr, Kettleson EM, Ramaswami B, Chen DR, Biswas P. Charge reduced electrospray size spectrometry of mega- and gigadalton complexes: whole viruses and virus fragments. Anal Chem. 2006;78(3):844-52.

25. TJ J, Bothner B, Traina J, Benner WH, Siuzdak G. Electrospray ion mobility spectrometry of intact viruses. Spectroscopy. 2004;18:31-6.

26. Pease LF 3rd. Physical analysis of virus particles using electrospray differential mobility analysis. Trends Biotechnol. 2012;30(4):216-24.

27. Pease LF 3rd, Lipin DI, Tsai DH, Zachariah MR, Lua LH, Tarlov MJ, et al. Quantitative characterization of virus-like particles by asymmetrical flow field flow fractionation, electrospray differential mobility analysis, and transmission electron microscopy. Biotechnol Bioeng. 2009;102(3):845-55.

28. Pease LF 3rd, Tsai DH, Brorson KA, Guha S, Zachariah MR, Tarlov MJ. Physical characterization of icosahedral virus ultra structure, stability, and integrity using electrospray differential mobility analysis. Anal Chem. 2011;83(5):1753-9.

29. Laschober C, Wruss J, Blaas D, Szymanski WW, Allmaier G. Gasphase electrophoretic molecular mobility analysis of size and stoichiometry of complexes of a common cold virus with antibody and soluble receptor molecules. Anal Chem. 2008;80(6):2261-4.

30. Kaddis CS, Lomeli SH, Yin S, Berhane B, Apostol MI, Kickhoefer VA, et al. Sizing large proteins and protein complexes by electrospray ionization mass spectrometry and ion mobility. J Am Soc Mass Spectrom. 2007;18(7):1206-16.

31. Malm L, Hellman U, Larsson G. Size determination of hyaluronan using a gas-phase electrophoretic mobility molecular analysis. Glycobiology. 2012;22(1):7-11.

32. Weiss VU, Golesne M, Friedbacher G, Alban S, Szymanski WW, Marchetti-Deschmann M, et al. Size and molecular weight determination of polysaccharides by means of nano electrospray gas-phase electrophoretic mobility molecular analysis (nES GEMMA). Electrophoresis. 2018;39(9-10):1142-50.

33. Szymanski WW, Bacher G, Allmaier G. Applicability of nanoaerosol techniques for measurements of high-mass biopolymers and complexes. In: Szymanski WW, Wagner P, Itoh M, Ohachi T, editors. Nanostructured materials and their applications. Vienna: Facultas; 2004. p. 157-66.

34. Mouradian S, Skogen JW, Dorman FD, Zarrin F, Kaufman SL, Smith LM. DNA analysis using an electrospray scanning mobility particle sizer. Anal Chem. 1997;69(5):919-25.

35. Saucy DA, Ude S, Lenggoro IW, Fernandez de la Mora J. Mass analysis of water-soluble polymers by mobility measurement of charge-reduced ions generated by electrosprays. Anal Chem. 2004;76(4):1045-53.

36. Ude S, Fernandez de la Mora J, Thomson BA. Charge-induced unfolding of multiply charged polyethylene glycol ions. J Am Chem Soc. 2004;126(38):12184-90.

37. Muller R, Laschober C, Szymanski WW, Allmaier G. Determination of molecular weight, particle size, and density of high number generation PAMAM dendrimers using MALDITOF-MS and nES-GEMMA. Macromolecules. 2007;40(15): 5599-605.

38. Dudkiewicz A, Wagner S, Lehner A, Chaudhry Q, Pietravalle S, Tiede K, et al. A uniform measurement expression for cross method comparison of nanoparticle aggregate size distributions. Analyst. 2015;140(15):5257-67.

39. Grombe R, Charoud-Got J, Emteborg H, Linsinger TP, Seghers J, Wagner $\mathrm{S}$, et al. Production of reference materials for the detection and size determination of silica nanoparticles in tomato soup. Anal Bioanal Chem. 2014;406(16):3895-907.

40. Hinterwirth H, Wiedmer SK, Moilanen M, Lehner A, Allmaier G, Waitz T, et al. Comparative method evaluation for size and sizedistribution analysis of gold nanoparticles. J Sep Sci. 2013;36(17): 2952-61.

41. Kallinger P, Weiss VU, Lehner A, Allmaier G, Szymanski WW. Analysis and handling of bio-nanoparticles and environmental nanoparticles using electrostatic aerosol mobility. Particuology. 2013;11(1):14-9.

42. Weiss VU, Lehner A, Kerul L, Grombe R, Kratzmeier M, Marchetti-Deschmann M, et al. Characterization of cross-linked gelatin nanoparticles by electrophoretic techniques in the liquid and the gas phase. Electrophoresis. 2013;34(24):3267-76.

43. Tsai DH, DelRio FW, Pettibone JM, Lin PA, Tan J, Zachariah MR, et al. Temperature-programmed electrospray-differential mobility analysis for characterization of ligated nanoparticles in complex media. Langmuir. 2013;29(36):11267-74.

44. Havlik M, Marchetti-Deschmann M, Friedbacher G, Winkler W, Messner P, Perez-Burgos L, et al. Comprehensive sizedetermination of whole virus vaccine particles using gas-phase 
electrophoretic mobility macromolecular analyzer, atomic force microscopy, and transmission electron microscopy. Anal Chem. 2015;87(17):8657-64.

45. Wieland K, Ramer G, Weiss VU, Allmaier G, Lendl B, Centrone A. Nanoscale chemical imaging of individual chemotherapeutic cytarabine-loaded liposomal nanocarriers. Nano Res. 2019;12(1): 197-203.

46. Weiss VU, Wieland K, Schwaighofer A, Lendl B, Allmaier G. Native nano-electrospray differential mobility analyzer (nES GEMMA) enables size selection of liposomal nanocarriers combined with subsequent direct spectroscopic analysis. Anal Chem. 2019;91(6):3860-8.

47. Engel NY, Weiss VU, Marchetti-Deschmann M, Allmaier G. nES GEMMA analysis of lectins and their interactions with glycoproteins - separation, detection, and sampling of noncovalent biospecific complexes. J Am Soc Mass Spectrom. 2017;28(1):7786.

48. Bacher G, Szymanski WW, Kaufman SL, Zollner P, Blaas D, Allmaier G. Charge-reduced nano electrospray ionization combined with differential mobility analysis of peptides, proteins, glycoproteins, noncovalent protein complexes and viruses. J Mass Spectrom. 2001;36(9):1038-52.

49. Allmaier G, Laschober C, Szymanski WW. Nano ES GEMMA and PDMA, new tools for the analysis of nanobioparticles-protein complexes, lipoparticles, and viruses. J Am Soc Mass Spectrom. 2008;19(8):1062-8.

50. Buck CB, Thompson CD. Production of papillomavirus-based gene transfer vectors. Curr Protoc Cell Biol. 2007. https://doi.org/10. 1002/0471143030.cb2601s37.

51. Tycova A, Prikryl J, Foret F. Reproducible preparation of nanospray tips for capillary electrophoresis coupled to mass spectrometry using 3D printed grinding device. Electrophoresis. 2016;37(7-8): 924-30.

52. van den Heuvel RH, van Duijn E, Mazon H, Synowsky SA, Lorenzen K, Versluis C, et al. Improving the performance of a quadrupole time-of-flight instrument for macromolecular mass spectrometry. Anal Chem. 2006;78:7473-83.

53. Lorenzen K, Versluis C, van Duijn E, van den Heuvel RHH, Heck AJR. Optimizing macromolecular tandem mass spectrometry of large non-covalent complexes using heavy collision gases. Int $\mathbf{J}$ Mass Spectrom. 2007;268(2-3):198-206.

54. Contino NC, Pierson EE, Keifer DZ, Jarrold MF. Charge detection mass spectrometry with resolved charge states. J Am Soc Mass Spectrom. 2013;24(1):101-8.

55. Weiss VU, Kerul L, Kallinger P, Szymanski WW, MarchettiDeschmann M, Allmaier G. Liquid phase separation of proteins based on electrophoretic effects in an electrospray setup during sample introduction into a gas-phase electrophoretic mobility molecular analyzer (CE-GEMMA/CE-ES-DMA). Anal Chim Acta. 2014;841:91-8.

56. Wang Q, Kaltgrad E, Lin T, Johnson JE, Finn MG. Natural supramolecular building blocks. Wild-type cowpea mosaic virus. Chem Biol. 2002;9(7):805-11.

57. Catalina MI, van den Heuvel RH, van Duijn E, Heck AJ. Decharging of globular proteins and protein complexes in electrospray. Chemistry. 2005;11(3):960-8.

58. Laschober C, Kaddis CS, Reischl GP, Loo JA, Allmaier G, Szymanski WW. Comparison of various nano-differential mobility analysers (nDMAs) applying globular proteins. J Exp Nanosci. 2007;2(4):291-301.
Publisher's note Springer Nature remains neutral with regard to jurisdictional claims in published maps and institutional affiliations.

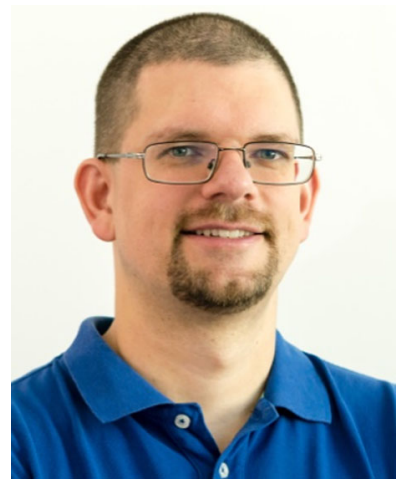

Victor U. Weiss is an Assistant Professor in the research group "Mass Spectrometric Bio- and Polymer Analytics" at TU Wien, Institute of Chemical Technologies and Analytics, Vienna, Austria. In his research, he focusses on the characterization and detection of nanoparticle material (organic, inorganic, and biological, e.g., liposomes, viruses, and virus-like particles) by application of electrophoretic techniques (liquid-phase electrophoresis in the capillary and the chip format as well as gas-phase electrophoresis). Furthermore, he works on the on- and offline hyphenation of gas-phase electrophoresis to orthogonal analysis methods.

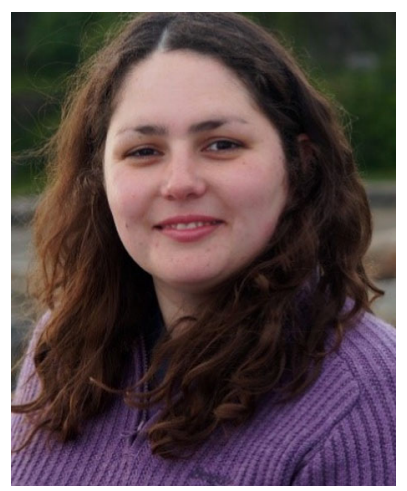

Ronja Pogan is a $\mathrm{PhD}$ student at Charlotte Uetrecht's lab at the Heinrich Pette Institute, Leibniz Institute for Experimental Virology in Hamburg, Germany. She studied biology in Hamburg. Her work within the Horizon 2020 project VIRUSCAN aims to characterize viral particles with mass spectrometry focusing on capsid assembly and stability.

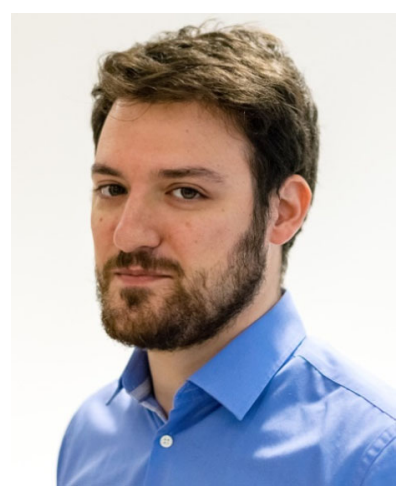

Samuele Zoratto is a $\mathrm{PhD}$ student in the research group "Mass Spectrometric Bio- and Polymer Analytics" at TU Wien, Institute of Chemical Technologies and Analytics, Vienna, Austria. His current project focusses on methods development for the characterization of nano(bio)particles (i.e., virus-like particles) by means of gas-phase electrophoresis (nES GEMMA), atomic force microscopy (AFM), and native mass spectrometry (nMS). 


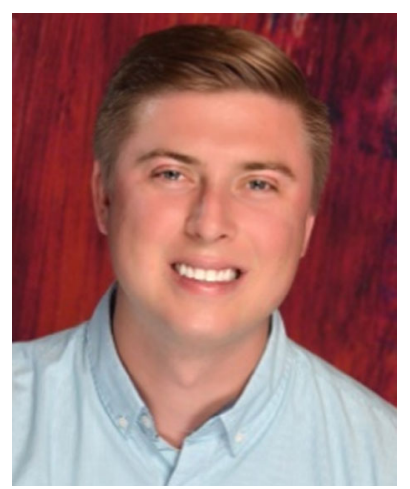

Kevin M. Bond is a PhD candidate in Professor Martin F. Jarrold's research lab at Indiana University in Bloomington, Indiana. His research in the Jarrold group has primarily involved investigation of the assembly pathways and products of virus-like particles and the analysis of viral vaccines using charge detection mass spectrometry.

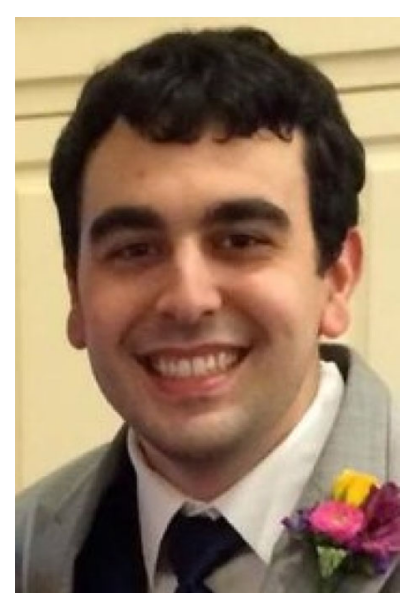

Nicholas Lyktey is a $\mathrm{PhD}$ candidate in Professor Martin F. Jarrold's research lab at Indiana University in Bloomington, Indiana. His research in the Jarrold group has primarily involved investigation of the gene therapy vector $\mathrm{AAV}$ as well as studies of micellular formation using charge detection mass spectrometry.

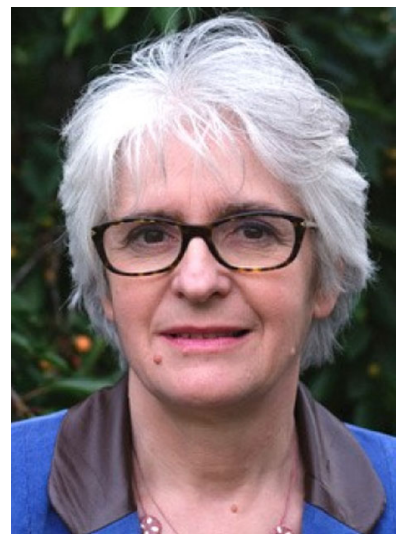

DNA into the host cell.
Pascale Boulanger is Head of the Team Bacteriophage T5 of the Institute for Integrative Biology of the Cell (I2BC) in Gif-surYvette, France. She has been studying for many years the mechanisms of infection of bacteria by their natural predators, the bacteriophages, using both in vivo and in vitro approaches. She has been a major contributor in deciphering the structure of phage T5 particle as well as the molecular basis of phage/host recognition and delivery of viral

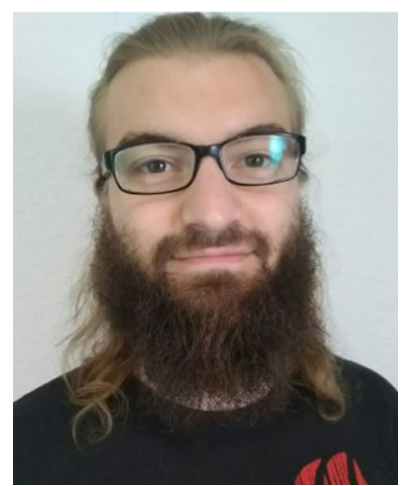

Martin F. Jarrold is FullProfessor and Robert and Marjorie Mann Chair in the Chemistry Department at Indiana University in Bloomington, Indiana. His current research focusses on the development and applications of charge detection mass spectrometry.

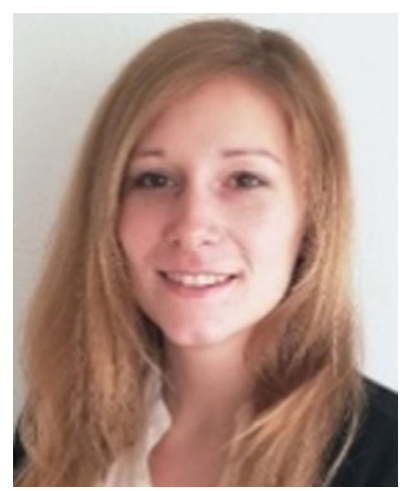

Dominik Pahl is a $\mathrm{PhD}$ student in the Institute of Cellular Virology in Münster, Germany. His work is focused on structural features of the human papillomavirus capsid during cell entry.
Nicole Puffler graduated with her Master's from TU Wien where she studied "Technical Chemistry." She focused on analytical chemistry and wrote her bachelor and master thesis within the Institute of Chemical Technologies and Analytics (TU Wien, Vienna, Austria). 

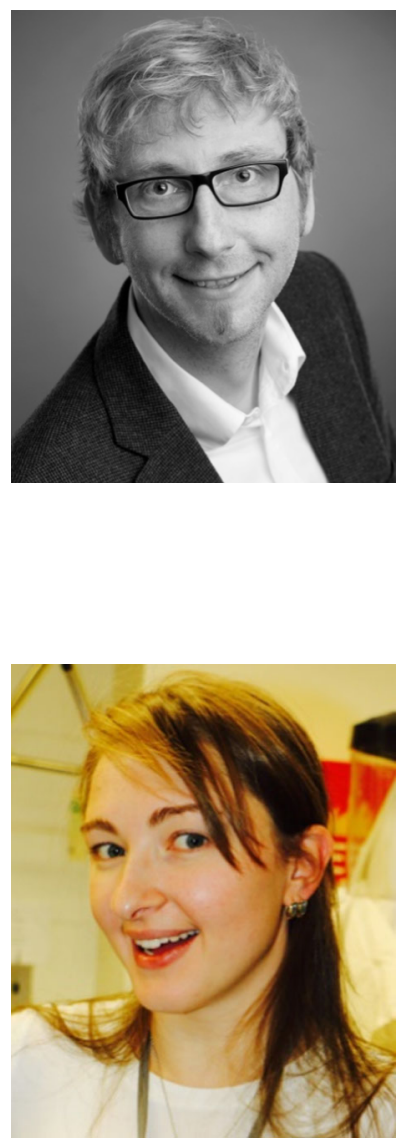

Mario Schelhaas is Director of the Institute of Cellular Virology at the University of Münster, Germany. His work is focussed on structural and cell biological aspects of virus entry (particularly of small non-enveloped DNA viruses) into host cells with a strong emphasis on imaging techniques.

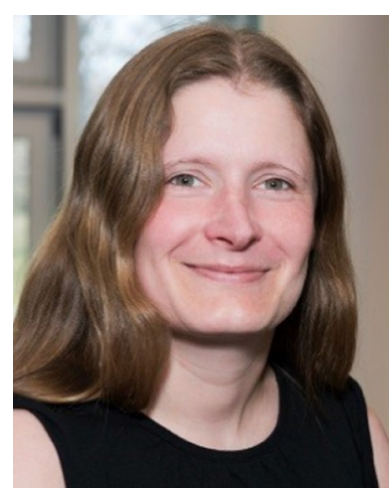

Ekaterina Selivanovitch is a 4th year chemistry $\mathrm{PhD}$ student in the Douglas Lab at Indiana University. Her current research is based on the development of biomimetic materials using viruslike particles. She received a B.S. in chemistry from St. Francis College in Brooklyn, NY, and a M.S. in chemistry from St. John's University in Queens, NY.
European XFEL.

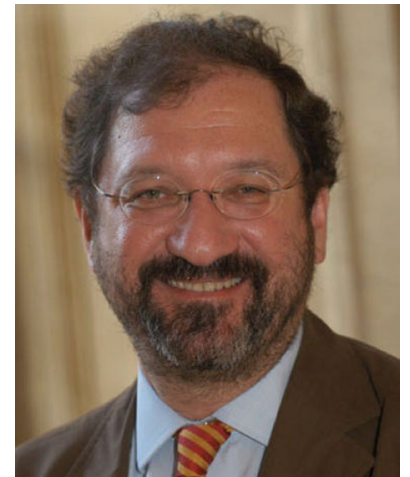

Charlotte Uetrecht is Junior Group Leader at the Heinrich Pette Institute, Leibniz Institute for Experimental Virology, Hamburg, Germany, and guest scientist at the European XFEL $\mathrm{GmbH}$, Schenefeld, Germany. Her research focuses on dynamics of viral structures using structural mass spectrometry. She studied biochemistry in Potsdam, Germany, obtained her $\mathrm{PhD}$ from Utrecht University in the lab of Albert Heck and did a postdoc in Uppsala, Sweden, and at
Günter Allmaier is Full Professor of Analytical Chemistry in the research group “Mass Spectrometric Bio- and Polymer Analytics" at TU Wien, Institute of Chemical Technologies and Analytics, Vienna, Austria. Since the beginning of the 1980s, he has been working in the field of mass spectrometry and analysis of bioactive compounds with emphasis on therapeutic proteins and proteomics/lipidomics. During the last 15 years, he has also been engaged in the field of electrophoretic separation in the liquid and gas phase of various classes of biomolecules and nano(bio)particles. 